\title{
Influence of Psychological Stress on Periodontal Diseases
}

\author{
Larissa Marques Storto Soares ${ }^{a}$,Ana Emilia Farias Pontes ${ }^{\text {b }}$, Fernanda de Oliveira Bello Corrêa ${ }^{c}$,Cleverton Corrêa Rabelo \\ ${ }^{a}$ Undergraduate research student, School of Dentistry, Federal University of Juiz de Fora (UFJF), Governador Valadares Campus, Brazil.

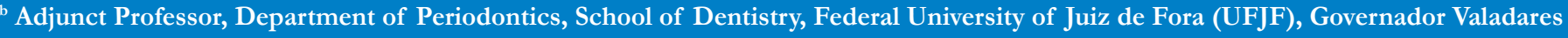 \\ Campus, Brazil. \\ ${ }^{\mathrm{c}}$ Associated Professor, Department of Periodontics, School of Dentistry, Federal University of Juiz de Fora (UFJF), Governador \\ Valadares Campus, Brazil.
}

\begin{abstract}
Introduction: The association between periodontal disease and stress has been questioned for a almost a century, however, it still represents an unexplored field of research with several orphaned questions of conclusive answers. Objective: To evaluate the relationship between periodontal disease and stress. Methodology: Searches were performed with descriptors related to periodontal diseases and psychological factors in the following databases: Pubmed, Embase, Lilacs. Were identified and included studies that deal with the relationship between stress and periodontal disease and /or that emphasize the role of this psychosocial factor in the progression of periodontal disease. Conclusion: Most studies have shown a positive relationship between periodontal disease and stress, however, further research needs to be developed to confirm stress as a risk factor for periodontal disease.
\end{abstract}

KEYWORDS: Psychological stress, Periodontal disease, Risk factors

\section{INTRODUCTION}

Since the middle of the last century, research has been carried out to seek evidence on the role of stress in the development of periodontal diseases. Stress is defined as a non-specific response of the organism to stimuli that counteract its homeostasis, ${ }^{1}$ and this relationship between stress and systemic diseases is explained by hormonal changes and behavioral changes that are precisely induced by stress. ${ }^{2}$ The search for homeostasis leads to the activation of allostatic systems, generating an energy expenditure in the body, known as allostatic charge. When this activation occurs in an excessive way, the phenomenon called allostatic overload occurs, where physical and mental pathologies can develop. ${ }^{3}$

It is known that stress is a risk factor for systemic diseases, such as cardiovascular diseases. Inability to defend one's rights, difficulty expressing feelings, and emotional stress are important factors in the magnitude of cardiovascular reactivity in response to stressful events experienced by mild hypertensive patients. According to the V Hypertension Guidelines (2006), hypertensive patients must undergo psychological training to develop ways to cope with excessive stress, to avoid its negative consequences. ${ }^{4}$ Stress, when not relieved, has a negative impact on health, and when uncontrolled, mediates or contributes to problems ranging from cardiovascular damage to impaired cognition, due to the possible neurodegeneration it causes. ${ }^{5}$
This psychosocial behavioral factor has also been increasingly associated with the pathogenesis of the periodontal disease. In the analysis of humoral immunity, an evident relationship was found between serum concentrations of stress-related proteins and periodontal disease. ${ }^{6}$ Several psychological disorders have shown an association with periodontitis, as well as with the progression of periodontal disease. $^{7}$

When the body has its state of homeostasis challenged, the stress cascade is activated so that the body makes the necessary physiological and metabolic changes to deal with this demand. When the body experiences a stressful event, the hypothalamus releases corticotropin-releasing hormone $(\mathrm{CRH})$, resulting in the release of adrenocorticotropic hormone $(\mathrm{ACTH})$, into the general circulation. ACTH acts on the adrenal cortex, which releases specific glucocorticoid species in the blood, which in turn, act negatively to complete the release of $\mathrm{CRH}$. The body tries to keep glucocorticoid levels within a limit, and interference at any axis level influences the other components through feedback loops. Over- or underproduction of cortisol can result in Cushing's and Addison's diseases, respectively, however, less severe deregulation of the Hypothalamus-Pituitary-Adrenal (HPA) axis can also have negative consequences, such as visceral fat deposition and cardiovascular disease (atherosclerosis ). ${ }^{8}$

By itself, stress is not harmful, but it becomes harmful when the stress load overcomes the individual's ability to adjust and 
he begins to experience its negative consequences. On the other hand, when the individual can cope with the stressful experience, the organism is able to return to the state before homeostasis, of well-being. ${ }^{9}$ In short, what matters is not how much stress the living being is exposed to, but how and what means it has to deal with this demand.

As for distress, this psychosocial manifestation is characterized by the inability to overcome stressful demands, leading to the breakdown of individual well-being. The distress has a multidimensional character, since multiple events, seen by the individual as a threat, can generate it. ${ }^{10}$ It is known as an emotional disorder that can impact people's social interactions and daily lives ${ }^{11}$ and is associated with an adaptation difficulty that impairs the individual's feeling of well-being, that is, the agents that perform the construction of psychological wellbeing and satisfaction, fail. ${ }^{12}$

To be mentally healthy is not to be free of symptoms or psychological disorders. Mental health is defined by the degree of manifestation of well-being and distress that human beings demonstrate. ${ }^{13}$ The elevated and prolonged levels of distress associated with the reduced sense of well-being help to make subjects vulnerable to the disorder. The degree and how the distress is experienced can be evident by the degree of dysfunctionality presented. ${ }^{14}$ The relationship between anguish, depression, and anxiety raises the question whether distress, if left untreated, can lead to depression. ${ }^{15}$

\section{STRESS AND PERIODONTAL DISEASE}

As neglect of care with oral hygiene, a bacterial invasion is facilitated, the immune response becomes weaker, and consequently periodontal disease is reinforced by stress. ${ }^{16}$ Chronic stress is known to activate the HPA axis, with the consequent release of the hormone cortisol that leads to a decrease in the defenses of the immune system, for days or months. ${ }^{17}$ Some studies carried out in animals where epinephrine was injected, it was observed migration of lymphocytes from Organs lymphoid organs into the blood and lymphatic stream and a reduction in the effectiveness of their functional activity. ${ }^{18}$ In another experiment, there was an increase in Natural Killer cells and neutrophils after administration of catecholamines, adrenaline and norepinephrine, and a drastic decrease in $\mathrm{T}$ and $\mathrm{B}$ cells in plasma levels. ${ }^{19}$ These experimental animal studies support the hypothesis that the stressed individual's immune response capacity in the face of the bacterial attack of periodontal disease becomes impaired, which then facilitates the disease's progression.

An experimental animal trial showed that there were no significant differences $(\mathrm{P}>0.05)$ in the inflammatory infiltrate, loss of insertion or bone resorption between the two groups of animals restricted and subjected to different levels of stress, which perhaps can confirm the thesis that the destructive effect of stress does not depend on the time in which the individual is exposed, but on how he supports these stressful loads. ${ }^{20}$
The HPA (hypothalamus-pituitary-adrenal) axis is activated by chronic stress and leads to a decrease in the number of circulating leukocytes. This fact occurs both during a period of severe stress and in the late response to stress. ${ }^{21}$ Confirming this fact, a study carried out with students found that, during the exam week, students had a delay in the healing of mucosal wound, when compared to their healing abilities during the vacation period. During this testing period, healing was approximately $40 \%$ slower. $^{22}$

Glucocorticoids regulate several bodily functions, including the response of inflammatory cells to microorganisms. Hyperactivation of the HPA axis generates less regulation of cell-regulated immunity and greater regulation of antibodymediated immunity. ${ }^{23}$ A study corroborated this thesis, showing that as the level of glucocorticoid in human blood increased, there was suppression in the production of interleukins 12 (IL12) and an increase in the production of interleukin 10 (IL10). This type of cytokine production alters the inflammatory response, which changes from cell-mediated to a reaction with increased antibody production. For the authors, stress can suppress the function of Th1 cells, leading to a change in the production of cytokines, which is now carried out by Th2 cells, which can have very important consequences in the progression of periodontitis and other infectious diseases. ${ }^{24}$

An experimental animal trial confirmed that stress worsens bone loss caused by periodontal disease since by inhibiting chronic stress in rats, with fluoxetine, it was observed that this medication was able to reduce bone loss aggravated by stress. ${ }^{25}$ Likewise, another experimental animal trial demonstrated this fact. Through the use of diazepam, the authors state that the group subjected to stress showed an increase in alveolar bone loss and an increase in IL-6 and IL-1B, while the stressed group treated with diazepam, demonstrated a decrease in IL levels. -6 , IL-1B and loss of alveolar bone. ${ }^{26}$

Some studies call attention because they do not show differences in the prevalence or extent of periodontal disease, between depressed and non-depressed patients. ${ }^{27}$ These divergences in results between studies relating periodontal disease and psychological disorders, such as stress and depression, may perhaps be justified by the fact that the selfperception of health and illness is different among individuals, and the way in which each faces their psychological condition too. In other words, a patient with signs of depression may not perceive himself as such, while other individuals may not be diagnosed with the disease and still be multi-compliant. Patients can be registered as being depressed, not being, or as not being depressed, even if they are. The disparity between experience and perception of health problems suggests that people deny and repress the stress of their lives. ${ }^{28}$ In addition, there are different means of assessing stress, which can result in different results and diagnoses. Currently, standardized scales are used to assess and measure psychological distress, however, several of them were created without a conceptual 
basis and are still used.13 Therefore, researchers are looking for more accurate means of assessing stress, such as the measurement of cortisol concentration, since its concentration demonstrates how much was activated for the first phase of allostasis and for how long the suppressive response of the body's initial reaction to stress, vigorous.9 There are also mathematical means of measuring stress, where a derivative is used, derived from the trapezoid formula, in which the cortisol values are inserted in this formula, ${ }^{29}$ measurement of stress through capillary cortisol, in which it is possible to check the long-term stress level, ${ }^{30}$ biochemical measures, where the concentrations of catecholamines in plasma and urine are evaluated, as they are activated in the initial reaction to stress, ${ }^{31}$ and the physiological measures of stress, which are related to the levels of wear or changes in the functional pattern of systems or structures of the organism, such as, for example, total cholesterol, waist-hip circumference, and fat deposit. $^{32}$

In an investigation of the role of psychological disorders, such as depression, stress and anxiety in the progression of periodontitis in advanced stages, periodontal clinical and radiological evaluations were carried out in 108 individuals and the authors concluded that it is possible to accept the hypothesis of a correlation between the two variables. ${ }^{33}$ One study evaluated the outcome of periodontal treatment in depressed patients. The presence or absence of depression was the main independent variable, having been determined by the presence of any diagnostic code for depression in the patient's record. After a year of follow-up, patients with depression were more than twice as likely to experience sub-median results from periodontal treatment compared to patients without depression. Also according to these authors, the regression models demonstrate that the increase in the depth of the scholarship is significantly predicted by factors of occupational stress-type A personality, perception of physical problems, lack of information about changes in the work environment, as well as behaviors health benefits to maintain high health status. What draws attention is the fact that there was no difference in the prevalence or extent of periodontal disease at the beginning of the study between depressed and non-depressed patients. ${ }^{27}$

A study investigated the effect of occupational stress on periodontal health and the authors concluded that the participants needed to control their health, which was reflected in their inconsistent responses regarding the perception of health problems and the experience of symptoms related to stress. ${ }^{34}$ In a cross-sectional study, stress, cortisol and periodontitis were associated. For this, the patients' saliva was collected at three times of the day (morning, afternoon and night). Cortisol levels were positively associated with the extent and severity of periodontitis. Although the authors collected cortisol in just one day, they associated this measure with a questionnaire and Lipp's Stress Inventory, which reinforces the veracity of the result found. ${ }^{35}$ Likewise, authors associated the measurement of salivary cortisol with a stress questionnaire from the National Institute for Stress at Work and Health, to relate periodontitis to self-reported stress, and salivary cortisol as a means of identifying work stress. For that, 180 workers from two industries were evaluated and found that $82 \%$ of the participants reported being stressed, and of the sixty participants who presented saliva samples, almost 3/4 showed positive work stress. According to the authors, the chance of having periodontitis is six times greater in people who have positive work stress, compared to those who do not. ${ }^{36}$

In a study on the effects of stress under non-surgical periodontal treatment, chemical and biological markers from patients with chronic periodontal disease were used. Initial levels, biological markers and clinical parameters were similar in groups of stressed and non-stressed patients. Elastase levels were higher in the group of stressed patients $(p>0.05)$, and these showed a poorer response to periodontal treatment. ${ }^{37}$ Another study evaluated the influence of stress and anxiety on the response to periodontal treatment in patients with chronic periodontal disease. According to the authors, stressed patients did not show a reduction in the depth of the pocket, which reinforces the role of stress for the progression of periodontal disease, as well as for the failure of periodontal therapy. ${ }^{38}$

A case-control study related periodontal disease to psychosocial factors. For this, in addition to assessing the depth of probing levels, insertion level and bleeding at probing, four tests were applied to assess stress, anxiety and depression. Through bivariate and multivariate logistic regression analyzes, the results showed a positive association between periodontitis, age, male gender, smoking and educational level. However, the bivariate analysis did not show significance between psychosocial factors and periodontal disease. According to Reis (1997), only multivariate statistical analysis allows us to assess the joint role of variables and determine the influence or importance of each one. ${ }^{39}$

Stress was evaluated as a possible risk factor for periodontal diseases through a systematic review with the search for scientific evidence in this correlation. Most of the included studies demonstrated a correlation between stress and periodontal disease, however, the authors highlighted the heterogeneity of the studies and the risk of bias in the lack of standardization of their methodologies. The importance of standardizing measures was reaffirmed as a means of achieving similar results when it is desired to correlate the same factors. The criteria for periodontal evaluation and psychological evaluation questionnaires should be standardized, however, we perceive different methodologies in the studies, both concerning the diagnosis of periodontal disease, and the instruments used for the diagnosis of mental stress. ${ }^{40}$

\section{CONCLUSION}

Understanding the dynamics of stress and how it impacts people's habits and behaviors, studies included in this review 
showed the influence of stress both on the progression of periodontal disease and on its onset. From these revised articles, it was not possible to conclude whether stress can be considered a risk factor for periodontal disease, as it is still necessary that studies use a standardized methodology in determining the diagnosis and measuring stress levels. Only in this way will we be able to confirm, from evidence, stress as being or not a risk factor for periodontitis.

\section{REFERENCES}

1. Selye $H$. The general adaptation syndrome and the diseases of adaptation. Journal of Clinical Endocrinology \& Metabolism. 1946;6(2): 117-230.

2. Genco RJ, Ho AW, Kopman J, Grossi SG, Dunford RG, Tedesco LA. Models to Evaluate the Role of Stress in Periodontal Disease. 1998 Jul;3(1): 288-302.

3. McEwen BS, Seeman T. Protective and Damaging Effects of Mediators of Stress: Elaborating and Testing the Concepts of Allostasis and Allostatic Load. Annals of the New York Academy of Sciences. 1999; 896(1): 30-47.

4. Brasil. V Diretrizes Brasileiras de Hipertensão Arterial. São Paulo: Sociedade Brasileira de Hipertensão; 2006.

5. Lipp MEN, Frare A, dos Santos FU. Efeitos de variáveis psicológicas na reatividade cardiovascular em momentos de stress emocional. Estudos de Psicologia (Campinas). 2007; 24(2):161-167.

6. Lopatin DE, Shelburne CE, Poperin NV, Kowalski CJ, Bagramian RA. Humoral Immunity to Stress Proteins and Periodontal Disease. Journal of Periodontology.1999; 70(10):1185-1193.

7. Vettore MV, Leão ATT, Monteiro da Silva AM, Quintanilha RS, Lamarca GA. The Relationship of stress and anxiety with chronic periodontitis. J Clin Periodontol. 2003; 30: 394-402.

8. Miller DB, O'Callaghan JP. Neuroendocrine aspects of the response to stress. Metabolism. 2002;51(6): 5-10.

9. McEwen BS. Central effects of central hormones in health and disease:understading the proctetive and damaging effects of stress and stress mediators. European Journal of Pharmacology. 2008; 583: 174 -185 .

10. Sparrenberger F, dos Santos I, Lima RDC. Epidemiologia do distress psicolgico: estudo transversal de base populacional. Rev Saúde Pública. 2003;37(4):434-9.

11. Wheaton B. The twain meet: distress, disorder and the continuing conundrum of categories (comment on Horwitz). Health: An Interdisciplinary Journal for the Social Study of Health, Illness and Medicine. 2007; 11(3):303-319.

12. Connor JJ, Rueter MA. Parent-child relationships as systems of support or risk for adolescent suicidality. Journal of Family Psychology. 2006; 20(1):143-155.

13. Drapeau A, Marchand A, Beaulieu-Prévost D. Epidemiology of Psychological Distress. Mental Illnesses - Understanding, Prediction and Control, Luciano L'Abate. Montréal, Canadá: IntechOpen; 2012.

14. Westerhof GJ, Keyes CLM. Mental Illness and Mental Health: The Two Continua Model Across the Lifespan. Journal of Adult Development. 2009; 17(2):110-119.

15. Horwitz AV. Distinguishing distress from disorder as psychological outcomes of stressful social arrangements. Health: An Interdisciplinary Journal for the Social Study of Health, Illness and Medicine. 2007; 11(3): 273-289.

16. Jr Ringsdorf WM, Cheraskin E. Emotional status and the periodontium. J Tenn State Dent Assoc. 1969Jan; 49(1):5-18.

17. Oppermann RV, Alchieri JC, de Castro GD. Efeitos do estresse sobre a imunidade e doença periodontal. R Fac Odontol Porto Alegre. 2002Dez; 43(2): 52-59.
18. Benschop RJ, Rodriguez-Feuerhahn M, Schedlowski M. (1996). Catecholamine-Induced Leukocytosis: Early Observations, Current Research, and Future Directions. Brain, Behavior, and Immunity. 1996; 10(2): 77-91.

19. Harris TJ, Waltman TJ, Carter SM, Maisel AS. Effect of prolonged catecholamine infusion on immunoregulatory function: Implications in congestive heart failure. Journal of the American College of Cardiology. 1995;26(1): 102-109.

20. Gaspersic R, Stiblar-Martincic D, Skaleric U. Influence of restraint stress on ligature-induced periodontitis in rats. Eur J Oral Sci. 2002;110: 125129.

21. Ader R, Cohen N, Felten D. Psychoneuroimmunology: interactions between the nervous system and the immune system. The Lancet. 1995;345(8942): 99-103.

22. Marucha PT, Kiecolt-Glaser JK, Favagehi M. Mucosal Wound Healing Is Impaired by Examination Stress. Psychosomatic Medicine. 1998;60(3): $362-365$.

23. Daynes RA, Araneo BA. (1989). Contrasting effects of glucocorticoids on the capacity of T cells to produce the growth factors interleukin 2 and interleukin 4. European Journal of Immunology. 1989; 19(12): 23192325 .

24. Elenkov IJ, Chrousos GP. Stress Hormones, Th1/Th2 patterns, Pro/ Anti-inflammatory Cytokines and Susceptibility to Disease. Trends in Endocrinology \& Metabolism. 1999;10(9): 359-368.

25. Aguiar JCA, Gomes EPP, Fonseca-Silva T, Velloso NA, Vieira LT, Fernandes MF, et al. Fluoxetine reduces periodontal disease progression in a conditioned fear stress model in rats. Journal of Periodontal Research. 2013;48(5): 632-637.

26. Gomes EPP, Aguiar JCA, Fonseca-Silva T, Dias LC, Moura-Boas KP, Roy A, et al. Diazepam reverses the alveolar bone loss and hippocampal interleukin 1 beta and interleukin- 6 enhanced by conditioned fear stress in ligatureinduced periodontal disease in rats. J Periodontal Res. 2013; 48: $151-158$.

27. Elter JR, White BA, Gaynes BN, Bader JD. Relationship of Clinical Depression to Periodontal Treatment Outcome. Journal of Periodontology. 2002; 73(4):441-449.

28. Donald H, Donald O. The Psychological Stresses of Intensive Care Unit Nursing. Psychosomatic Medicine, Vol. 34, No. 2; 1972.

29. Pruessner JC, Kirschbaum C, Meinlschmid G, Hellhammer DH. Two formulas for computation of the area under the curve represent measures of total hormone concentration versus time-dependent change. Psychoneuroendocrinology. 2003; 28(7):916-931.

30. Raul JS, Cirimele V, Ludes B, Kintz P. Detection of physiological concentrations of cortisol and cortisone in human hair. Clinical Biochemistry. 2004; 37(12): 1105-1111.

31. McCarty R, Gold PE. Catecholamines, Stress, and Disease: A Psychobiological Perspective. Psychosomatic Medicine. 1996; 58(6): 590-597.

32. Evans GW, Kim P, Ting AH, Tesher HB, Shannis D. Cumulative risk, maternal responsiveness, and allostatic load among young adolescents. Developmental Psychology. 2007; 43(2):341-351.

33. Laforgia A, Corsalini M, Stefanachi G, Pettini F, Di Venere D. Assessment of Psychopatologic Traits in a Group of Patients with Adult Chronic Periodontitis: Study on 108 Cases and Analysis of Compliance during and after Periodontal Treatment. International Journal of Medical Sciences. 2015;12(10): 832-839.

34. Freeman R, Goss S. Stress measures as predictors of periodontal disease a preliminary communication. Community Dent Oral Epidemiol.1993;21: 176-7.

35. Hilgert JB, Hugo FN, Bandeira DR, Bozzetti MC. (2006). Stress, Cortisol, and Periodontitis in a Population Aged 50 Years and Over. Journal of Dental Research.2006;85(4): 324-328.

36. Atri M, Srivastava D, Kharbanda J, Bugalia A, Yousuf A, Anup N. Occupational Stress, Salivary Cortisol, and Periodontal Disease: A 
Clinical and Laboratory Study. J Int Oral Health. 2015 Sep;7(9): 65-9.

37. Bakri I, Douglas CWI, Rawlinson A. (2013). The effects of stress on periodontal treatment: a longitudinal investigation using clinical and biological markers. Journal of Clinical Periodontology. 2013;40(10): 955-961.

38. Vettore M, Quintanilha RS, Monteiro da Silva AM, Lamarca GA, Leão ATT. The influence of stress and anxiety on the response of non-surgical periodontal treatment. J Clin Periodontol 2005; 32: 1226-1235.
39. Castro GDC, Oppermann RV, Haas AN, Winter R, Alchieri JC. Association between psychosocial factors and periodontitis: a case-control study. J Clin Periodontol 2006; 33: 109-114.

40. Peruzzo DC, Benatti BB, Ambrosano GMB, Nogueira-Filho GR, Sallum EA, Casati MZ, et al. A Systematic Review of Stress and Psychological Factors as Possible Risk Factors for Periodontal Disease. Journal of Periodontology. 2007;78(8): 1491-1504.

Citation: Larissa Marques Storto Soares, Ana Emilia Farias Pontes, Fernanda de Oliveira Bello Corrêa, Cleverton Corrêa Rabelo , "Influence of Psychological Stress on Periodontal Diseases" American Research Journal of Dentistry, vol 2, no. 1, 2020, pp. 1-5.

Copyright @ 2020 Larissa Marques Storto Soares, et al. This is an open access article distributed under the Creative Commons Attribution License, which permits unrestricted use, distribution, and reproduction in any medium, provided the original work is properly cited. 